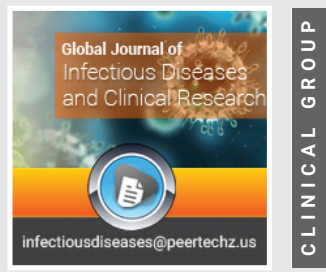

\title{
Clinical study on blood
}

\section{routine and dynamic changes, condition and prognosis of hand foot and mouth disease} (EV71)

\section{Ling-liang Yao* and Le Kang}

Department of Infection, Loudi Central Hospital/Loudi Clinical College Affiliated to Nanhua University/ Loudi Clinical Postgraduate Training Base of Nanhua University, Loudi, Hunan, China

Received: 31 March, 2021

Accepted: 17 April, 2021

Published: 20 April, 2021

*Corresponding author: Ling-liang Yao, Department of Infection, Loudi Central Hospital/Loudi Clinical College Affiliated to Nanhua University/Loudi Clinical Postgraduate Training Base of Nanhua University, Loudi, Hunan, China, Tel: 13973879171;

E-mail: yaolingliang@sina.com

Keywords: Hand foot and mouth disease; Routine blood; The illness; The prognosis

https://www.peertechzpublications.com

\section{Check for updates}

\section{Abstract}

Objective: To explore the relationship between the total number of white blood cells and the ratio of neutrophils to lymphocytes in the blood of hand-foot-mouth disease (EV71) and the condition of the disease, and to explore the relationship between the dynamic changes of blood samples above the early severe cases and the trend of prognosis.

Methods: 216 outpatient and hospitalized cases according to the condition can be divided into: (I group) in critical group of 17 cases, (II group) early intensive group 167 cases, 32 cases (III group) ordinary group. Age, course of disease, total number of white blood cells and neutrophil ratio were compared. According to the dynamic changes of the above blood images, the patients in the early severe group were further divided into: group A, 49 patients in the group with increased ratio of white blood cells and neutrophils. In group B, the ratio of leukocyte to lymphocyte was increased in 53 patients. In group C, there were 67 cases of leukocyte decrease and lymphocyte ratio increase.

Results: (1) statistical analysis of various indicators including age, course of disease, total number of white blood cells and neutrophil ratio of patients with different disease conditions: there was no statistically significant difference in disease course between the groups $(F=1.38 P>0.05)$, while there were statistically significant differences among the groups in age, total number of white blood cells and neutrophil ratio ( $F$ value: $4.9,14.15,25.98$, respectively). P < 0.01 ). (2) in group A, 4 of the 49 cases developed into critically ill patients, and the conversion rate of critically ill patients was $8.16 \%$; in group $B$ and group $C$, the conversion rate of critically ill patients was 0 ; in group $A$, the conversion rate of critically ill patients was statistically significant compared with the other two groups $(P<0.01)$.

Conclusion: HFMD (EV71) is related to the total number of white blood cells and the ratio of neutrophils. The changes of the dynamic ratio of leukocytes and neutrophils to lymphocytes have clinical significance for the trend of prognosis.

HFMD outbreaks occur all the year round. The genotype of HFMD enterovirus that broke out in loudi city in 2010 was mainly EV71 [1]. Hand, foot and mouth disease (EV71) with increasing aggravation of blood picture [2], along with the ratio of neutrophils and lymphocytes change at the same time, through to our hospital on April 1, 2010 to May 31, 2010 critically ill, early intensive group and normal group (EV71) cases of hand, foot and mouth disease blood routine analysis and comparison, and cases of early intensive group dynamic blood picture observation, found that the routine blood leukocytes and neutrophils ratio is closely related to the disease, early severe cases of leukocytes and neutrophils and lymphocytes ratio dynamic change is closely related to the prognosis of trend, will now report about information is as follows:

\section{Objects and methods}

\section{The object of study}

All the cases for loudi center hospital in April 2010, 31 solstice on May 31, 2010 in the fever outpatient and hospitalized 
cases in the acute phase of (early severe cases through routine blood review more than one), both through anal loudi CDC try sampling or sampling of EV71 diagnosed cases of hand, foot and mouth (sporadic cases confirmed by sampling, gather and outbreak cases confirmed by sampling). Clinical classification and treatment were classified according to the guidelines for the prevention and control of HFMD issued by the ministry of health. Early severe case group (early severe case group): persistent high fever and presentation of neurological involvement. Such as: poor spirit, lethargy, easy to surprise, delirium; Headache, vomiting; Limb jitter, myoclonic, nystagmus, ataxia, eye movement disorders; Weakness or acute delayed paralysis; Convulsions. Signs of meningeal irritation, tendon reflex weakened or disappeared; Critical case group (critical case group) : frequent convulsions, coma and cerebral herniation occurred in one of the following cases. (2) dyspnea, cyanosis, bloody frothy sputum, lung rura, etc. (3) shock and other circulatory dysfunction [2]. Among them, 32 cases were in the general group, 20 cases were in the male group, and 12 cases were in the female group. Early severe disease group: 167 cases, male: 105 cases, female: 62 cases; Critical condition group: 17 cases, male: 11 cases, female: 6 cases. There was no significant difference between the sexes in each group, which was comparable $(\mathrm{P}>0.05)$.

\section{Research methods}

Illness group and research steps: according to the guide on admission criteria whether the condition above cases can be divided into: (I group) group, the group (II) in acute severe early group, the group (III) group; All outpatient and hospitalized cases in the first day of the hospital to check blood routine, for early cases severe group according to the requirements of the guide as soon as possible to give small doses of hormones (methylprednisolone 1-2 mg/kg) intervention, 12 to $24 \mathrm{~h}$ after the review of routine blood, root tree, foot and mouth disease in acute and recovery at different stages in the routine blood total number of white blood cells and neutrophils and lymphocytes ratio change to the above cases can be divided into three groups: group A, white blood cells and neutrophils ratio increased groups: higher total number of white blood cells, neutrophils ratio increased and reduced lymphocyte ratio; In group $\mathrm{B}$, the leucocyte and lymphocyte ratio increased: the total number of white blood cells increased, neutrophil ratio decreased and lymphocyte ratio increased or the total number of white blood cells decreased, neutrophil ratio increased and lymphocyte ratio decreased. In group C, WBC decreased and lymphocyte ratio increased: total number of WBC decreased, neutrophil ratio decreased and lymphocyte ratio increased.

\section{Statistical methods}

The data were expressed as mean \pm standard deviation $(\mathrm{x} \pm \mathrm{S})$. SPSS11.5 statistical software was used for statistical processing of the data. Analysis of variance was used for comparison among the measurement data groups, $\mathrm{q}$ test was used for pairwise comparison, and chi-square test was used for enumeration data.

\section{Results}

\section{Different condition}

I, II group, III comparison between way: differences between groups of course no statistical significance $(P>0.05)$, age, routine blood total number of White Blood Cells (WBC) and Neutrophils ratio $(\mathrm{N})$ group differences were statistically significant $(\mathrm{P}<0.01)$. See Table 1. I group, II group , III group comparison between groups : duration of each group showed no significant difference $(\mathrm{P}>0.05)$, age, blood leukocyte count (WBC) and Neutrophil ratio $(\mathrm{N})$ in each group differences were statistically significant $(\mathrm{P}<0.01)$. Table 1 .

\section{Cases in the early severe group were further divided into group $A$, group $B$ and group $C$ for inter-group com- parison}

There was no statistical significance in age and gender difference between each group $(P>0.05)$. The differences in mortality were statistically significant $(\mathrm{X} 2=166.25, \mathrm{P}<0.01)$. The mortality of group A was significantly higher than that of group B and group C. Are shown in Table 2.

Table 1: Age, course of disease, total number of white blood cells and neutrophi ratio of patients with different diseases.

\begin{tabular}{|l|c|c|c|c|c|} 
& The number of & \multirow{2}{*}{$\begin{array}{c}\text { Age } \\
\text { cases }\end{array}$} & Course of the & \multicolumn{2}{|c|}{ Routine blood } \\
\cline { 5 - 6 } & & disease & WBC $\left(\times 10^{9} / \mathrm{L}\right)$ & $\mathrm{N}(\%)$ \\
\hline I group & 17 & $1.8 \pm 0.38$ & $2.2 \pm 0.36$ & $22.8 \pm 2.1$ & $88.3 \pm 1.1$ \\
\hline II group & 167 & $2.5 \pm 0.44$ & $1.8 \pm 0.13$ & $13.8 \pm 0.73$ & $72.5 \pm 1.8$ \\
\hline III group & 32 & $3.20 \pm 0.05$ & $1.8 \pm 0.9$ & $9.2 \pm 0.72$ & $65.2 \pm 2.2$ \\
\hline F 4.91 .3814 .1525 .98 & & & & \\
\hline P $<0.01>0.05<0.01<0.01$ &
\end{tabular}

Table 2: Blood routine changes and prognosis trends in 167 cases with early severe disease.

\begin{tabular}{l|l|l|l} 
grouping & Early intensive & Critically ill & Critical illness transformation(\%)
\end{tabular}

\begin{tabular}{c|c|c|c|}
\hline Agroup & 49 & 4 & 8.16 \\
\hline Bgroup & 55 & 0 & 0 \\
\hline Cgroup & 63 & 0 & 0 \\
\hline A total of & 167 & 4 & 2.39 \\
\hline
\end{tabular}

\section{Discussion}

On the one hand, a variety of enteroviruses can lead to HFMD, that is, there are differences in external causes of HFMD (virus virulence); On the other hand, there are differences in the immune function of enterovirus between different age groups and individuals. Enterovirus (EV71) infection leads to relatively high incidence and mortality of severe and critical diseases in infants and children under 3 years of age. In addition, there are physiological characteristics of infants and young children: compared with adults, the immune function of fetuses, newborns and children is relatively inadequate and in great changes, and there is a difference between individuals in the level of immune function. It is this external cause that leads to the relatively low immune function through the action of internal cause, which leads to the above results [3]. Due 
to the ineffective treatment of antibiotics and the extremely limited efficacy of antiviral drugs, the body mostly fights off viral infection through its own antiviral immune function. The immune function of organism can be divided into specific immune function and non-specific immune function, and specific immune function can be further divided into cellular immune function and humoral immune function. According to the research of zeng huihui [2] and yan xiufeng [4], the more severe HFMD is, the lower the cellular immune function will be. Theoretically speaking, the organism compensates more through humoral immunity and non-specific immune functions, and achieves the relative balance and stability of anti-infection (virus) immune functions through the interaction and regulation of the above three. According to yan xiufeng et al., with the aggravation of the disease, the level of immunoglobulin gradually increases, which indicates that humoral immunity in children with severe HFMD is hyperactive [4]. Non-specific immune function is compensated by cytokines in humoral factors and neutrophils in phagocytes [5]. We believe that the clinical critical hand-foot-mouth disease in the late stage of the sustained high fever, and blood, c-reactive protein and other non-specific indicators significantly increased, are related to the non-specific immune inflammatory response compensatory enhancement. A large number of clinical data showed that most of the critically ill hand-foot-mouth disease (EV71) had significantly increased blood picture, blood glucose, c-reactive protein and other indicators, and the clinical situation in our department was basically similar to the above report. In this paper, the changes of blood routine (blood picture) were discussed. As can be seen from Table 3: (1) with the increase of onset age, the body's autoimmune function is enhanced and the disease is relatively mild. The age of the critical group is mainly in the age range of 1-2 years, indicating the lowest autoimmune function in this age group, which is consistent with the experimental results of zeng huihui [3] et al. It may be related to the time when maternal antibodies gradually disappear and autoimmunity has not been established. (2) the heavier the disease, the higher the ratio of white blood cells and neutrophils, the heavier the systemic inflammatory response. In the critical group, there was one case with the shortest history of 12 hours and the most severe systemic inflammatory response. The ratios of WBC $35.2 \times 109 / \mathrm{L}$ and $\mathrm{N} 95 \%$, respectively. Most of the patients in this group had missed the opportunity of rescue and treatment when they came to the hospital. As can be seen from Table 1 of this group of cases, the heavier the disease, the higher the ratio of white blood cells and neutrophils, and the worse the prognosis. It is worth discussing whether its high mortality is related to organ failure caused by systemic inflammatory response. (3) the three groups of patients in the course of statistical comparison is not statistically significant $(\mathrm{P}>0.05)$, but it can be seen from the Table: the serious group of patients in the course of longer than the other two groups, may be more serious illness, rash is not typical and with the grass-roots hospital medical staff diagnosis and treatment experience is insufficient.The increase of white blood cells in HFMD (EV71) was not completely consistent with the severity of the disease. Further studies showed that the dynamic changes of white blood cells and various cell proportions in early severe cases were
Table 3: Disease patient's age, duration of blood leukocytes and neutrophils ratio grouping.

\begin{tabular}{|l|c|c|c|c|c|}
\hline & \multirow{2}{*}{$\begin{array}{c}\text { Number of cases } \\
\text { (persons ) }\end{array}$} & $\begin{array}{c}\text { Age } \\
\text { (years ) }\end{array}$ & duration & \multicolumn{2}{|c|}{ blood } \\
\cline { 5 - 6 } & (days ) & WBC $(\times 10 \% / \mathbf{~}$ ) & N (\%) \\
\hline I group & 17 & $1.8 \pm 0.38$ & $2.2 \pm 0.36$ & $22.8 \pm 2.1$ & $88.3 \pm 1.1$ \\
\hline II Group & 167 & $2.5 \pm 0.44$ & $1.8 \pm 0.13$ & $13.8 \pm 0.73$ & $72.5 \pm 1.8$ \\
\hline III group & 32 & $3.20 \pm 0.05$ & $1.8 \pm 0.9$ & $9.2 \pm 0.72$ & $65.2 \pm 2.2$ \\
\hline F value 4.9 1.3814 .1525 .98 & & & \\
\hline P-value $<0.01>0.05<0.01<0.01$ &
\end{tabular}

Table 4: 167 patients with early severe cases blood grouping and dynamic change trend prognosis.

\begin{tabular}{|c|c|c|c|}
\hline Grouping & $\begin{array}{c}\text { Early Severe Cases The Number Of } \\
\text { Critically III }\end{array}$ & $\begin{array}{c}\text { Patients In } \\
\text { Critical }\end{array}$ & $\begin{array}{c}\text { Conversion } \\
\text { Rate \% }\end{array}$ \\
\hline A group & 49 & 4 & 8.16 \\
\hline B Group & 55 & 0 & 0 \\
\hline C Group & 63 & 0 & 0 \\
\hline Total & 167 & 4 & 2.39 \\
\hline
\end{tabular}

Grouping: A group of 494 8.16, Group B 5500, Group C 6300, Total 16742.39

closely related to the trend of prognosis of the disease. Table 4 in each case group of early severe diseases, with the progress of disease course, although some cases of immune injury [4] had different degrees of aggravation of clinical symptoms, only 4 cases of group A developed into critical diseases, all of which died of pulmonary edema and pulmonary hemorrhage. Two of them were given endotracheal intubation earlier, and were not given oxygen by positive pressure or other therapeutic intervention, but the effect was little, and the disease continued to progress and death. All the 4 cases of death in this group presented progressive increase in the ratio of white blood cells to neutrophils, which may be related to the low body specific immune (cell and body fluid) function and the compensatory enhancement of non-specific immune inflammatory response. This further supports the view of organ failure caused by systemic inflammatory response syndrome. Although patients in group B also showed a transient increase in the total number of white blood cells, patients in both groups (group B and group C) showed an increase in the proportion of lymphocytes, which may be related to humoral immune function compensation and had a good prognosis.Clinical observation found that this group of cases as there are several ways to develop critical cases: (1) with small doses of hormones (methylprednisolone) after treatment, the short-term startle, jitter, nervous system symptom such as progressive increase, (2) dynamic blood routine observation, total number of white blood cells for more than 24 by $7 \times 109 \mathrm{~h} / \mathrm{L}$, (3) total number of white blood cells have obvious rise early, but the proportion of neutrophils and lymphocytes changes relative lag. It can be seen that dynamic blood routine observation is particularly important for early severe cases. Due to the convenience of routine blood test, combined with dynamic observation of clinical manifestations, it is of great clinical significance to monitor early severe cases in outpatient department and judge the trend of prognosis.

\section{References}

1. Ying $H$, Jinru W (2010) Analysis of the epidemic situation and etiology of HFMD in Loudi City. Practical Preventive Medicine 17: 195-196. 
2. Huihui Z, Yan G, Xuefei D (2010) Clinical study on T lymphocyte subsets in peripheral blood of children with HFMD [J]. Chinese Journal of Infectious Diseases 28: 82-85.

3. Yun Z, Zhenpeng D, Ping LV (2001) Comparative study on T lymphocyte phenotype of fetal and neonatal cord blood. J Immunol 17: 379-382.
4. Xiufeng Y, Hui Y, Yi Y (2011) Analysis of immune status of hospitalized children in Shanghai in 2009 [J]. Chinese Journal of infectious diseases 29: 41-43.

5. Shaoji Y (2005) Epidemiology. Beijing: People's Health Press 4.
Discover a bigger Impact and Visibility of your article publication with

\section{Peertechz Publications}

\section{Highlights}

* Signatory publisher of ORCID

* Signatory Publisher of DORA (San Francisco Declaration on Research Assessment)

* Articles archived in worlds' renowned service providers such as Portico, CNKI, AGRIS, TDNet, Base (Bielefeld University Library), CrossRef, Scilit, J-Gate etc.

* Journals indexed in ICMJE, SHERPA/ROMEO, Google Scholar etc.

* OAI-PMH (Open Archives Initiative Protocol for Metadata Harvesting)

* Dedicated Editorial Board for every journa

* Accurate and rapid peer-review process

* Increased citations of published articles through promotions

* Reduced timeline for article publication

Submit your articles and experience a new surge in publication services (https://www.peertechz.com/submission).

Peertechz journals wishes everlasting success in your every endeavours.

Copyright: @ 2021 Yao LL, et al. This is an open-access article distributed under the terms of the Creative Commons Attribution License, which permits unrestricted use, distribution, and reproduction in any medium, provided the original author and source are credited.

Citation: Yao LL, Kang L (2021) Clinical study on blood routine and dynamic changes, condition and prognosis of hand foot and mouth disease (EV71). Glob J Infect Dis Clin Res 7(1): 033-036. DOI: https://doi.org/10.17352/2455-5363.000043 